\title{
On Experience in Measuring the Consolidation of Modern Russian Society
}

\author{
Vyacheslav V. Lokosov ${ }^{1}$, Vladimir L. Schultz ${ }^{1}$, Vladimir V. Ulyanov ${ }^{2}$ \\ ${ }^{1}$ Institute of Socio-Political Research of Russian Academy of Sciences, Moscow, Russia \\ ${ }^{2}$ Faculty of Computational Mathematics and Cybernetics, Moscow State University, Moscow, Russia \\ Email: ispiran@vmail.ras.ru, sentea@mail.ru
}

Received December $3^{\text {rd }}$, 2011; revised January $6^{\text {th }}$, 2012; accepted February $9^{\text {th }}, 2012$

\begin{abstract}
One of the main reasons for prolongation of the crisis of contemporary Russian society is a profound social disconnection, alienation of the leading segments of the society. The social consolidation is considered as a fundamental basis to overcome the crisis and to form the civil society and the Russian civil (political) nation. We suggest how the consolidation of Russian society could be measured applying the traditional understanding of the empirical material as semantic space. The empirical data consist from three all-Russian surveys carried out in 2007, 2009 and 2011. According to our analysis the level of consolidation of Russian society decreased in last two years. The respondents with middle and high income are most focused on the consolidation. We describe the profile of the consolidators and allocate the features that can be used to unite most of the population of all age groups and income levels. The social and political stability of Russian society depends on the direction in which the consolidation develops.
\end{abstract}

Keywords: Social Consolidation; Factors of Consolidation; Level of Consolidation; Indicative Measurements; Social Groups; Social Changes; Social and Political Stability

\section{Conceptual Justification}

The modern Russian society as the social system continues to gravitate to chaotic forms of reproduction and keeps a marginal social structure. One of the major reasons of prolongation and simultaneously a consequence of system crisis of the Russian society is deep social separation and alienation of its leading segments. A fragmented society, suffering from a "social entropy" and social anomy, is not able to increase its energy capacity, to mobilize itself and to take other actions needed for the effective development and finding adequate responses to the growing external challenges and internal threats (Danilov, 1998; Held et al., 1999; Osipov, 2007). After the neo-liberal "shock therapy" in $90 \mathrm{~s}$ it is necessary for Russia to pass through the stage of consolidation in order to transform the country into a new integrity. Therefore, social consolidation is seen as a fundamental basis for the development of the modern Russian society and as a tool of social technology to form the civil society and the Russian civil (political) nation (Schmitter, 1996; Lokosov \& Schultz, 2008).

The concept of "consolidation" combines two main semantic notion, which constitute the essence of attempts to fuse macroobjective and micro-subjective approaches to the description and explanation of social reality: the value of the objective integration of various structures of social system and subjective solidarity of people in their everyday life. Moreover, in this term there are no those connotations which direct at the Soviet ideological clichés about moral and political unity and social uniformity of a society.

\section{Methodical Scheme of the Analysis of the Empirical Material}

On the empirical level, consolidation is defined as the potential of association and self-organization of citizens, close to each other with respect to their attitudes, motivations, principles and beliefs. The consolidation potential is formed at the expense of the general "social conceptions" (Moscovici, 1984), i.e. concerning the steady, structured sets of images, attitudes, orientations of a respondent to socially significant phenomena, events, tendencies. Therefore, the personal attitudes, motivations and values of the respondents were analyzed as an empirical material for an explanation and understanding of

1) The bases of potential for social consolidation and its volume;

2) The objective trends of the changes in consolidation process of the modern Russian society;

3) The social conditions of a civil society formation and other social transformations connected with consolidation process.

We agree with the generally accepted position that strengthening the common identities of the population, spreading the attitudes, motivations, values and socio-psychological patterns shared by the majority are the indicators of the increasing of the consolidation in the society.

Our analysis is based on the traditional understanding of the empirical material as semantic space, i.e. the spatial-coordinate model of an individual or group system of attitudes. The semantic space is determined by two orthogonal axes, obtained as a result of factor analysis of indicators (Doctorov, 1994; Lokosov, 2011). The vertical axis reflects objective-institutional structure of a society. It has two poles: the north- "legitimation of social system" and the south- "alienation from social system". Interpretation of a horizontal axis reflects a subjective-individual attitude in the society. In the west end of the axis we have "asocial outlook", i.e. a set of attitudes of people who place themselves outside of society ("when everyone wants to act according to his own advantages all together will come to a result which is unfavorable to the society" 
(Kozlowski, 1998); in the east-“inter-social outlook”, i.e. a set of attitudes of people focused on social interaction and cooperation.

In the research we used data from three all-Russian surveys carried out in 2007, 2009 and 2011. They included approximately 7000, 2000 and 1500 randomly selected adults (18+) respectively from all federal districts. The questionnaires of the surveys with more than 50 questions (approximately 170 sub questions) were almost identical. They were completed in faceto-face interviews. The samples were stratified random samples with stratification according to gender, age and place of residence.

As leading features of consolidation we allocate:

- The social-collectivist value orientations in the majority of the population;

- The legitimation of the existing social order, the rejection of radical ways to change existing society;

- Existence of goals, interests, and values, which are shared by the majority of Russians, the patriotism of the majority;

- The localization of the social interests on the local level, in daily challenges;

- Increase of social activity and withdrawal from the paternalistic sentiments, if one understands by them the passive-dependent expectation of his own well-being.

The characteristics of dissolidation are the following:

- Social and political inequality, low levels of satisfaction with the quality of life for most people, a huge gap in income levels;

- Alienation from the political system, lack of fairness in social system, lack of confidence in the leading social and political institutions;

- An identity crisis, including a low level of civil identity;

- Lack of a legitimate state ideology, ambitious socio-economic mega-projects that provide social system with strategic target dimension and form the so-called common cause;

- Inefficiency of the existing system of social management, non-motivation of Russian elite, formed for the task of dismantling the Soviet system, to be constructive, creative and innovative.

\section{Construction and Analysis of Typological Groups}

One of the main considered typological groups is a set of so-called ideal or pure respondent-consolidators. We suggest measuring a level of consolidation in the modern Russian society in terms of a consolidator fraction. A respondent is called consolidator if he shares the following five features:

- Preference of reforms and refusal of radical changes of social system;

- Trust in political institutions;

- The value orientation to social interaction and to cooperation between people;

- Civil identity;

- Social activity and readiness to protect his own interests.

The first two characteristics correspond to northern vector of semantic space-legitimation of the social system. Three last features reflect the east vector-inter-social attitude.

We require that the consolidator possesses all five characteristics. By this reason the consolidator fraction in the sample and therefore in the whole population is not large. At the same time study of the consolidators helps to solve two problems. First, it shows a change in the social "core" of the consolidation process in time. Secondly, it allows to analyze the social composition of respondents-consolidators and their profile in terms of other indicators included in questionnaires. The size of ideal group of consolidators decreased recently (see Figure 1): in 2007 it was equal to $10,8 \%$ of the whole sample, in $2009-12.6 \%$ and in 2011 - 5.9\% with standard errors (standard deviation divided by the square root of the sample size) equal to $0.4 \%, 0.7 \%$ and $0.6 \%$ respectively. The corresponding P-values (independent sample t-test with non-constant variance) for the results for pairs of years 2007-2009 and 2009-2011 equal to 0.030 and 0.000 respectively. Therefore we see that in 2007-2009 the level of consolidation of the Russian society grew slightly. But two years later it decreased significantly. It is quite possible that because of crisis in finance and economy in 2009, the factors connected with dissolidation started to play the leading role (Gorshkov, 2010). In the semantic space we watch the change of vector from the desired north-east direction to south-west what corresponds to disintegration of the society. From methodological point of view the changes can be explained

- By the decline in trust of respondents to the political institutions, including the decreased confidence in the activities of the president and the government;

- By strengthening of the skeptical perception of the existing society;

- By weakening of the civil identity and the self-identification relatively to place of residence.

At the same time it has been increased the fraction of the respondents who prefer to choose "do not know" alternative. For example, the percentage of the respondents who refused to assess the state of interethnic relations increased from $7 \%$ in 2007 to $21 \%$ in 2011. For inter-confessional relations we have $11 \%$ and $24 \%$ respectfully. Moreover, simultaneously we get corresponding decline in fraction of the respondents who assess the relations as normal or benevolent. Respondents with average and high level of income (on self-assessment of this level on a scale of buying opportunities) are mostly oriented to consolidation (see Table 1).

Analysis of the group of consolidators shows that in the modern Russian society the propensity for consolidation is shown, first of all, by the people having middle or high level of incomes. It can be explained by the fact that they are better adapted for new social realities, more focused on legitimation of existing social system and more socially active. For example,

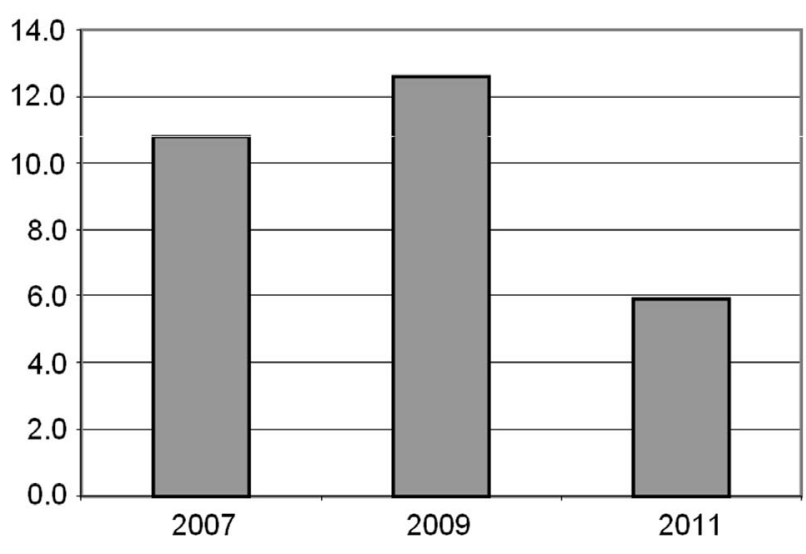

Source: Institute of Socio-Political Research of Russian Academy of Sciences.

Figure 1.

Change of Consolidator fraction in Russia among adults 18+, 2007$10.8 \%$, 2009-12.6\%, 2011-5.9\%. 
Table 1.

Distribution of respondents according to income level, in percents of the respondents in the whole sample and in the group of consolidators (Russian Federation, survey of 2011 among adults 18+).

\begin{tabular}{|c|c|c|}
\hline Income level & Sample & Consolidators \\
\hline High (enough money to buy an apartment or a car) & 10 & 13 \\
\hline $\begin{array}{l}\text { Middle (enough money to buy consumer durables, } \\
\text { or just on housing, food and clothing) }\end{array}$ & 58 & 69 \\
\hline $\begin{array}{l}\text { Low (money, at best, only enough to buy food and } \\
\text { clothing) }\end{array}$ & 32 & 18 \\
\hline
\end{tabular}

the readiness to protect their interests showed $77 \%$ of the respondents with high income and only $47 \%$ of the group with the lowest income. People with high income are consolidated to a greater extent within their own group as well. Therefore, one can conclude that the society is rather consolidated when its members are socially active and rely on themselves mainly. In other words, the individualization of the society in the new social conditions does not prevent its consolidation.

Among the age groups the orientation to consolidation is most expressed among 40 - 49 years old respondents as well as among those who work in the non-state sector of the economy, the inhabitants of the cities with the population from 100 thousand up to 1 million people. Probably, life in rural areas, small towns and megacities is not suitable for the tendency to consolidation.

\section{Points of Consolidation}

In terms of the semantic space the characteristics of the consolidators correspond to "north-east" attitudes (see Table 2).

In Table 2 we gave five indicators which clearly demonstrate that aiming at the consolidation may positively affect the mass consciousness. In the research it was confirmed that the most important differences in values, political orientations, social well-being and in other indicators of mass consciousness are observed among the age groups and the groups with different income levels. The study of identities revealed an interesting empirical fact: the greatest number of respondents (around 60\%) feels the closeness and similarity with people of their generation. This means that the Russian society in last years was structured, first of all, according to the generations. Today the senior, middle and younger generations act independently and opposing each other in some aspects. Therefore, the success of the society consolidation depends largely on the restoration of inter-generational continuity and mutual understanding of people with different income levels.

Following this assumption we study the answers according to the age groups and the groups with different income levels. The indicator was considered favorable for consolidation when there was no statistically significant correlation between answers in different groups provided that the answer was chosen by at least $30 \%$ of the respondents. For example, among 14 most acute social problems we discovered four issues, attitude to which is statistically independent of the age of the respondents and their level of income (see e.g. Fujikoshi, Ulyanov, \& Shimizu 2010). These four issues are: alcoholism and drug addiction; despotism of bureaucracy; inequality and stratification of population according to income level; environmental pollution. Consequently, around the decision of these four problems one can unite the overwhelming majority of the population of all age groups and income levels.
Table 2.

Distribution of respondents' answers (agreement with statements) in percents of the respondents in the whole sample and in the group of consolidators (Russian Federation, survey of 2011 among adults 18+).

\begin{tabular}{lcc}
\hline \multicolumn{1}{c}{ Statement } & Sample & Consolidators \\
\hline $\begin{array}{l}\text { Laws are not perfect, but they should be } \\
\text { always obeyed }\end{array}$ & 58 & 70 \\
$\begin{array}{l}\text { Russian society can make a breakthrough } \\
\text { in its development }\end{array}$ & 61 & 73 \\
$\begin{array}{l}\text { Human well-being depends primarily on the } \\
\text { person himself } \\
\text { Today in Russia it is possible to conduct } \\
\text { business without violating the law }\end{array}$ & 66 & 80 \\
$\begin{array}{l}\text { Elections are one of the main achievements of } \\
\text { democracy, they are necessary for political stability }\end{array}$ & 22 & 54 \\
\hline
\end{tabular}

Usually between 30 and $50 \%$ of the respondents are concerned with the problems of alcoholism, drug addiction and environmental pollution. The changes of these variables in 2007-2011 years have been insignificant. In contrast to the variable "the despotism of bureaucracy": the level of concern with this issue has increased from 28\% in 2007 to $42 \%$ in 2011. A similar trend was observed with the problem of inequality and stratification according to income level: the percentage of respondents ranked it as the most acute, increased from $13 \%$ in 2007 to $31 \%$ in 2011. These changes give the new points for consolidation of public opinion.

We identified 34 variables that have received more than $50 \%$ of respondents' votes, and on this basis they can be regarded as the points of consolidation for the Russian society, but further tightening of the conditions, e.g. taking into account the views of the respondents from the different age groups and income levels, reduced the number of these variables to 16 .

Hopes for realization of the potential for the consolidation of the Russian society still remain elusive. A low level of consolidation in 2011 leads to multi-social negative consequences. "Class" consciousness begins to take shape in poor circles of population, among whom it was great inertia of Soviet paternalism. Nowadays this inertia is outdated. Social-political stability of Russian society depends on how the consolidation of the "bottom" will happen. In these circumstances, the new constructive stage of transformation of the society is necessary. It can become the powerful stimulus of its consolidation.

\section{Acknowledgements}

The authors are grateful to reviewer's valuable comments that improved the manuscript.

\section{REFERENCES}

Danilov, A. N. (1998). Transitional society: Issues of system transformation. Minsk: Harvest.

Doctorov, B. Z. (1994). Russia in the European socio-cultural space. Sociological Journal, 3, 22-31

Fujikoshi, Y., Ulyanov, V. V., \& Shimizu, R. (2010). Multivariate statistics: High-dimensional and large-sample approximations. Hoboken, NJ: John Wiley and Sons.

Gorshkov, M. K. (Ed.). (2010). Social factors of consolidation of the Russian society: Sociological measurements. Moscow: Novyi Chronograph.

Held, D., McGrew, A., Goldblatt, D. \& Perraton, J. (1999). Global transformation: Politics, economics and culture. Stanford University Press. 


\section{V. LOKOSOV ET AL.}

Koslovski, P. (1982). Gesellschaft und Staat: ein unvermeidlicher Dualismus. Stuttgart: Klett-Cotta.

Lokosov, V. V. (Ed.). (2011). Modern methods for social and political research of a society. Proceedings of the international scientific conference, Moscow: ISPR, 21 May 2010.

Lokosov, V. V., \& Schultz, V. L. (2008). Basis of consolidation of the
Russian society, Sociological aspects. Moscow: ISPR.

Moscovici, S. (Ed.). (1984). Psychologie sociale. Paris: P.U.F.

Osipov, G. V. (2007). Sociology and society. Moscow: Norma.

Schmitter, F. (1996). Reflections about a civil society and democracy consolidation, Polis, 5, 16-27. 